\title{
Transcriptome Temporal and Functional Analysis of Liver Regeneration Termination
}

\author{
D. RYCHTRMOC ${ }^{1,3}$, L. HUBÁLKOVÁ ${ }^{2,3}$, A. VÍŠKOVÁ ${ }^{2,3}$, A. LIBRA $^{3}$, M. BUNČEK ${ }^{3}$, \\ Z. ČERVINKOVÁ ${ }^{1}$
}

${ }^{1}$ Department of Physiology and ${ }^{2}$ Department of Medical Biology and Genetics, Faculty of Medicine in Hradec Kralove, Charles University in Prague, Hradec Kralove, Czech Republic, ${ }^{3}$ GENERI BIOTECH s.r.o., Hradec Kralove, Czech Republic

Received March 16, 2012

Accepted May 22, 2012

\section{Summary}

Decades of liver regeneration studies still left the termination phase least elucidated. However regeneration ending mechanisms are clinicaly relevant. We aimed to analyse the timing and transcriptional control of the latest phase of liver regeneration, both controversial. Male Wistar rats were subjected to $2 / 3$ partial hepatectomy with recovery lasting from 1 to 14 days. Time-series microarray data were assessed by innovative combination of hierarchical clustering and principal component analysis and validated by real-time RT-PCR. Hierarchical clustering and principal component analysis in agreement distinguished three temporal phases of liver regeneration. We found 359 genes specifically altered during late phase regeneration. Gene enrichment analysis and manual review of microarray data suggested five pathways worth further study: PPAR signalling pathway; lipid metabolism; complement, coagulation and fibrinolytic cascades; ECM remodelling and xenobiotic biotransformation. Microarray findings pertinent for termination phase were substantiated by real-time RT-PCR. In conclusion, transcriptional profiling mapped late phase of liver regeneration beyond $5^{\text {th }}$ day of recovery and revealed 5 pathways specifically acting at this time. Inclusion of longer post-surgery intervals brought improved coverage of regeneration time dynamics and is advisable for further works. Investigation into the workings of suggested pathways might prove helpful in preventing and managing liver tumours.

\section{Key words}

Liver regeneration • Hepatectomy • Gene expression profiling • Termination • Rat

\section{Corresponding authors}

David Rychtrmoc, Charles University in Prague, Faculty of Medicine in Hradec Kralove, Department of Physiology, Simkova 870, 50038 Hradec Kralove, Czech Republic. Fax: +420 495518 772. E-mail: rychtrmocd@lfhk.cuni.cz and

Zuzana Červinková, Charles University in Prague, Faculty of Medicine in Hradec Kralove, Department of Physiology, Simkova 870, 50038 Hradec Kralove, Czech Republic. Fax: +420 495518 772. E-mail: wolff@lfhk.cuni.cz

\section{Introduction}

Liver regeneration is an intriguing phenomenon known to mankind since ancient times (DeFrances and Michalopoulos 2011, Tiniakos et al. 2010). Continued interest is supported by clinical use of living donor liver transplantations (Fausto and Riehle 2005, Ibrahim et al. 2005). Liver regeneration is an excellent model of synchronized and precisely controlled proliferative response of differentiated somatic cells which ultimately stops once the liver size and functions are sufficient for the organism. During regeneration profound metabolic adaptations enable both whole body homeostasis and proliferation of all hepatic cell populations.

Damaged liver tissue enters tightly regulated sequence of steps that are well able to restore lost mass and vital functions (Michalopoulos 2007). The regenerative response follows three distinct phases: initiation (priming), propagation (proliferation) and finally termination. While initiation has gained most of the research interest so far, termination is much less 
understood (Michalopoulos 2010). The same applies for metabolic alterations bound to respective phases of the process.

The most widely used model organisms for liver regeneration research are mice and rats (Palmes and Spiegel 2004) in which the process is truly fast. Most observations point to complete organ restoration in 5 to 14 days time. Within these borders some uncertainty remains, attributable to lack of widely accepted measure of regaining quiescent state. Fortunately origin of regeneration may be well controlled using a timehonoured 2/3 partial hepatectomy $(\mathrm{PH})$ introduced by Higgins and Anderson in 1931 (Higgins and Anderson 1931).

Transforming growth factor $\beta$ (TGF $\beta$ ) and activins are nowadays considered important for terminating the regenerative process (Gilgenkrantz and Collin de l'Hortet 2011). TGF $\beta$ inhibits hepatocyte proliferation both in vitro and in vivo (Nguyen et al. 2007). Also a role of extracellular matrix (ECM) components in regulating liver regeneration is increasingly appreciated (Mohammed and Khokha 2005) and was found essential for proper termination of liver regeneration (Apte et al. 2009). PPAR $\gamma$ upregulation inhibits hepatocyte proliferation once the cell count is sufficient (Yamamoto et al. 2008).

Regarding metabolic changes occurring in individual phases of regeneration, plenty of intermediates have been proven to also have a regulatory role, often acting via nuclear receptors (Delgado-Coello et al. 2011, Huang et al. 2006, Imai 2003, Wang et al. 2008).

As cessation of liver regeneration is focus of our longstanding interest we conducted the present study to thoroughly analyze genome-scale gene expression changes in this termination phase in a rat $2 / 3$ partial hepatectomy model. We included eight recovery intervals spanning to 14 days after surgery to provide due coverage of the time dynamics.

Regenerative proliferation of liver cells notably differs from that in hepatocarcinogenesis. Cells dividing to restore hepatectomised liver remain under proper cell cycle control. Identifying and targeting the altered regulatory pathways might help in treatment of liver tumours.

\section{Methods}

Seventy percent hepatectomy model

Male Wistar rats (7-8 weeks of age; $n=27$ ) were purchased from BioTest (Konarovice, Czech Republic) and housed under 12 hour light/dark cycle with free access to water and food. Partial hepatectomies (PH) were performed in 24 rats as described by Higgins and Anderson (Higgins and Anderson 1931). All animal experiments were conducted in accordance with European convention for the protection of vertebrate animals used for experimental and other scientific purposes (86/609/EHS; 1986) and approved by Ethics Committee of the Faculty of Medicine in Hradec Kralove.

After PH animals were bred and spontaneously recovered for $1,2,3,5,7,9,11$ and 14 days respectively ( $\mathrm{n}=3$ per interval). Control animals were three male Wistar rats not subjected to any surgical procedure (e.g. Day 0 group). All rats were sacrificed by aortic exsanguination at the designated day. Samples from either regenerating or quiescent liver tissue were snap frozen in liquid nitrogen and stored at $-70{ }^{\circ} \mathrm{C}$ for later total RNA isolation by TRI Reagent (Molecular Research Center Inc., Cincinnati, OH, USA). Whole body weights and wet liver weights were recorded to assess progression of organ regeneration. Extracted blood was used for preparing sera consequently subjected to biochemical assessment of alanine aminotransferase (ALT) and aspartate aminotransferase (AST) activities. These tests were performed at the Institute for Clinical Biochemistry and Diagnostics, University Hospital in Hradec Kralove.

\section{Microarray experimental procedures}

Dual-colour time-series microarray experiment was conducted under a common reference design (Dobbin and Simon 2002) using a pool of aminoallylaRNAs from five matched unoperated Wistar rats as the reference. Such design allowed for comparing all the different samples to each other. $500 \mathrm{ng}$ of each total RNA was amplified and converted to aminoallyl-aRNA using TargetAmp ${ }^{\mathrm{TM}}$ 1-Round Aminoallyl-aRNA Amplification Kit 101 kit (Epicentre, Madison, WI, USA). Individual samples were labelled either with DY-548 or DY-648 dyes (Dyomics GmbH, Jena, Germany). Balanced block design setting was carefully observed to eliminate dye bias (Dobbin et al. 2005). Twenty seven two-colour hybridizations were performed on $29 \mathrm{~K}$ Rat Arrays carrying 26962 oligonucleotide probes (Microarrays Inc., Huntsville, AL, USA) always combining individual and common reference samples. After hybridization, washing and drying, the slides were scanned, and the median intensities were computed. 
Table 1. Primer design data and selection of genes subjected to $q R T-P C R$ validation.

$\begin{array}{ll}\text { Official gene symbol } & \begin{array}{l}\text { qPCR assay code } \\ \text { (GENERI BIOTECH s.r.o.) }\end{array}\end{array}$ Reference sequence $\quad$ Exons spanned

\section{Housekeeping (reference) genes}

\begin{tabular}{llll}
\hline Surf1 & rSurf1_Q1 & NM_172068.1 & $4 / 5$ \\
Nup54 & rNup54_Q1 & NM_017361.1 & $11 / 12$ \\
Hmbs & rHmbs_Q2 & NM_013168.2 & $7 / 9$ \\
\hline
\end{tabular}

\section{Genes of interest}

\begin{tabular}{|c|c|c|c|}
\hline Hmgcs 2 & rHmgcs2_Q1 & NM_173094.1 & $5 / 6$ \\
\hline Pltp & rPltp_Q1 & XM_215939.4 & $10 / 11$ \\
\hline Mel & rMe1_Q1 & NM_012600.2 & $12 / 13$ \\
\hline Lypla1 & rLypla1_Q1 & NM_013006.1 & 9 \\
\hline Kngl & rKng1_Q1 & NM_012696.2 & $9 / 10$ \\
\hline Ppmld & rPpm1d_Q1 & NM_001105825.1 & $5 / 6$ \\
\hline Sesn3 & rSesn3_Q1 & NM_001108125.1 & $7 / 8$ \\
\hline Cesle & rCes1e_Q1 & NM_031565.2 & $10 / 11$ \\
\hline $\operatorname{Lcn} 2$ & rLcn2_Q1 & NM_130741.1 & $1 / 2$ \\
\hline Ang & rAng_Q1 & NM_001012359.1 & 1 \\
\hline Nat8 & rNat8_Q1 & NM_022635.1 & 1 \\
\hline Official gene symbol & Gene name & Entrez gene ID & KEGG pathway \\
\hline Hmgcs2 & $\begin{array}{l}\text { mitochondrial 3-hydroxy-3-methylglutaryl CoA } \\
\text { synthase }\end{array}$ & 24450 & rno03320 \\
\hline Pltp & phospholipid transfer protein & 296371 & rno03320 \\
\hline Mel & malic enzyme 1 & 24552 & rno03320 \\
\hline Lypla1 & lysophospholipase 1 & 25514 & rno00564 \\
\hline Kngl & kininogen 1 & 24903 & rno04610 \\
\hline Ppmld & $\begin{array}{l}\text { protein phosphatase 1D magnesium-dependent, } \\
\text { delta isoform }\end{array}$ & 287585 & rno04115 \\
\hline Sesn3 & sestrin 3 & 315427 & rno04115 \\
\hline Cesle & carboxylesterase $1 \mathrm{E}$ & 29225 & rno00983 \\
\hline Lcn2 & lipocalin 2 & 170496 & $\mathrm{~N} / \mathrm{A}$ \\
\hline Ang & angiogenin, ribonuclease, RNase A family, 5 & 497229 & N/A \\
\hline Nat8 & N-acetyltransferase 8 (GCN5-related, putative) & 64570 & N/A \\
\hline
\end{tabular}

Table 1 shows primer design data and a list of 11 qRT-PCR validated genes. Nine of them were among the 359 genes unique for the Late group as described. The exceptions were Lcn 2 included based on its prominent expression changes seen in microarray data and function in extracellular matrix remodelling and also Hmgcs2 owing to its association with PPAR signalling pathway and recent literature evidence (Yuan et al. 2011). KEGG pathway codes stand for: rno04610: Complement and coagulation cascades, rno04115: p53 signalling pathway, rno03320: PPAR signalling pathway, rno00983: Drug metabolism - other enzymes and rno00564: Glycerophospholipid metabolism.

\section{Microarray data analysis}

Finding differentially expressed genes (DEGs)

Statistical analysis was performed in the $\mathrm{R}$ computing environment using the Bioconductor package Linear Models for Microarray Analysis (limma; (Smyth 2004)). The $\log _{2}$-transformed ratios of green and red channel intensities (denoted as $\operatorname{LogFC}$ in further text) were normalized within array using printtiploess method (Smyth and Speed 2003). Average coefficients of differential expression among every group of treated samples and the common reference sample were used for hierarchical clustering and principal component analysis (PCA). Time contrasts were firstly defined referring to the control 
unoperated group and secondly between the three groups distinguished by clustering and PCA analyses (see below). Genes with $\operatorname{logFC}$ either above 1 or below -1 were considered significant, with such values meaning at least two-fold up- or downregulation respectively. The genes found to be significantly differentially expressed as assessed by multiple testing with decideTest function of limma package (keeping the $\log \mathrm{FC}$ cut-off of $|1|$ ) were further analyzed using The Database for Annotation, Visualization and Integrated Discovery (DAVID) (Huang et al. 2009a) and its Functional Annotation Tool encompassing gene enrichment analysis based on modified Fisher's Exact test (Huang et al. 2009b).

\section{Hierarchical clustering of microarray data}

To evaluate overall time course of expression changes and to find sample groups with similar temporal behaviour, we performed unsupervised heuristic hierarchical clustering with complete Euclidean distance as a metric. We employed hclust function available as a part of stats package for the R environment (Becker et al. 1988, Gordon 1999, Stekel 2003).

\section{Principal component analysis (PCA) of microarray data \\ PCA reduces dimensionality of gene expression} data by finding directions in the data space which account for greatest variability. The PCA analysis (Becker et al. 1988, Causton et al. 2003, Venables and Ripley 2002) was applied on centred and scaled gene expression data matrix and performed using prcomp function, included in stats package of $\mathrm{R}$ environment. We used the prcomp function as suggested by Thomas Girke (on-line; cited 20. 5. 2012).

Biochemical and weight data were processed in MS Excel (Microsoft, Redmond, WA, USA) and GraphPad Prism version 4.00 for Windows (GraphPad Software, San Diego, CA, USA) using ANOVA and Tukey's post hoc test with $p$ values $<0.05$ considered significant.

For RT-PCR validation, sets of two primers and a probe for 11 chosen target genes and three control genes were designed and synthesized in GENERI BIOTECH s.r.o. (Hradec Kralove, Czech Republic). Primer design summary is provided in Table 1. Selection of the three housekeeping genes was based on prior experimental validation of their expression stability. Selected genes (Surf1, Nup54, Hmbs) ranked best among eight genes tested as assessed by GeNorm and NormFinder tools, both gaining identical suitability order (Andersen et al. 2004,
Vandesompele et al. 2002). To avoid genomic DNA contamination, the primers were designed to span exon boundaries where possible. The hydrolyzation probes were labelled with FAM fluorescent reporter dye. One microgram of total RNA of each sample was reverse transcribed using oligo-dT primers (GENERI BIOTECH s.r.o., Hradec Kralove, Czech Republic) and MuMLV Reverse Transcriptase (Fermentas UAB, Vilnius, Lithuania) according to manufacturer's instructions. Realtime quantitative RT-PCR was performed on the iCycler (Bio-Rad Laboratories, Hercules, CA, USA) with amplification conditions: $95^{\circ} \mathrm{C}$ for $3 \mathrm{~min}$, and 50 cycles of each $95{ }^{\circ} \mathrm{C}$ for $10 \mathrm{~s}$ and $60^{\circ} \mathrm{C}$ for $30 \mathrm{~s}$. Each cDNA sample was analyzed in PCR triplicates and the mean of threshold cycle $(\mathrm{Ct})$ values was transformed into relative expression values using the equation according to Pfaffl (2001). The expression data were normalized by the geometric mean of Surf1, Nup54, and Hmbs expressions. Finally, the normalized expression of each gene of interest was compared to microarray results for every time point.

\section{Results}

\section{Partial hepatectomies}

All surgeries were shorter than 7 minutes and were well tolerated with no mortality.

\section{Liver weight recovery data}

In absence of widely accepted method to evaluate completeness of liver regeneration we employed whole organ weights related to total body weights to assess its progress. We could not directly measure whole liver weights at day of partial hepatectomy (PH); therefore we adopted a reasonable estimate by calculating it from weights of resected portion arbitrarily considered to be $70 \%$ of liver mass. Validity of this assumption and reproducibility of resection extent were confirmed in several rats before starting the present study (data not shown). We calculated two simple measures from raw weight data obtained on day of liver resection and on tissue collection. These were $\mathrm{PH}$ ratio and TC ratio and were gained as a fraction of whole liver weight before partial hepatectomy ( $\mathrm{PH}$ ratio) or at the moment of tissue collection (TC ratio) and $100 \mathrm{~g}$ of corresponding total body weight.

$\mathrm{PH}$ ratio $=$ calculated whole liver weight $/ 100 \mathrm{~g}$ total body weight on day of partial hepatectomy

$\mathrm{TC}$ ratio $=$ whole liver weight $/ 100 \mathrm{~g}$ total body weight on day of tissue collection 
Table 2. Overview of the weight data and parameters estimating progress of liver regeneration after PH.

\begin{tabular}{|c|c|c|c|c|c|}
\hline Parameter & Day 0 & Day 1 & Day 2 & Day 3 & Day 5 \\
\hline$I B W$ & $220.7 \pm 4.5$ & $230.7 \pm 23.4$ & $219.3 \pm 12.5$ & $230.0 \pm 27.8$ & $233.3 \pm 15.6$ \\
\hline$R L W$ & $\mathrm{~N} / \mathrm{A}$ & $7.9 \pm 0.9$ & $7.0 \pm 1.0$ & $7.3 \pm 0.5$ & $7.7 \pm 0.5$ \\
\hline$I W L W$ & $11.4 \pm 1.2$ & $11.3 \pm 1.3$ & $10.0 \pm 1.4$ & $10.5 \pm 0.8$ & $11.0 \pm 0.7$ \\
\hline$F B W$ & $220.7 \pm 4.5$ & $213.3 \pm 18.1$ & $221.3 \pm 9.1$ & $224.0 \pm 23.3$ & $250.7 \pm 12.2$ \\
\hline$F W L W$ & $11.4 \pm 1.2$ & $4.3 \pm 0.5$ & $6.6 \pm 0.3$ & $6.5 \pm 0.2$ & $8.9 \pm 0.7$ \\
\hline PH ratio & $5.1 \pm 0.5$ & $4.9 \pm 0.1$ & $4.6 \pm 0.6$ & $4.6 \pm 0.2$ & $4.7 \pm 0.1$ \\
\hline TC ratio & $5.1 \pm 0.5$ & $2.0 \pm 0.2$ & $3.0 \pm 0.1$ & $2.9 \pm 0.3$ & $3.6 \pm 0.3$ \\
\hline$\%$ LReg & $100 \%$ & $41 \pm 3 \%$ & $65 \pm 6 \%$ & $63 \pm 4 \%$ & $76 \pm 4 \%$ \\
\hline Parameter & Day 7 & Day 9 & Day 11 & Day 14 & \\
\hline$I B W$ & $218.3 \pm 19.3$ & $222.7 \pm 11.7$ & $208.3 \pm 3.5$ & $206.3 \pm 4.2$ & \\
\hline$R L W$ & $6.9 \pm 1.0$ & $7.9 \pm 0.8$ & $6.8 \pm 0.8$ & $6.7 \pm 0.7$ & \\
\hline$I W L W$ & $9.9 \pm 1.4$ & $11.3 \pm 1.1$ & $9.7 \pm 1.1$ & $9.5 \pm 1.0$ & \\
\hline$F B W$ & $253.3 \pm 26.2$ & $281.0 \pm 22.5$ & $270.3 \pm 19.5$ & $296.3 \pm 11.0$ & \\
\hline$F W L W$ & $9.2 \pm 2.1$ & $11.1 \pm 3.1$ & $10.5 \pm 2.1$ & $11.3 \pm 1.1$ & \\
\hline PH ratio & $4.5 \pm 0.2$ & $5.1 \pm 0.6$ & $4.6 \pm 0.5$ & $4.6 \pm 0.4$ & \\
\hline TC ratio & $3.6 \pm 0.5$ & $3.9 \pm 1.0$ & $3.9 \pm 0.5$ & $3.8 \pm 0.5$ & \\
\hline$\%$ LReg & $80 \pm 10 \%$ & $77 \pm 11 \%$ & $84 \pm 7 \%$ & $83 \pm 9 \%$ & \\
\hline
\end{tabular}

Table 2 presents summary of both measured and calculated weight parameters. Values are shown as mean \pm S.D. ( $n=3$ in each group). The meaning of row headers is as follows: IBW - initial body weight, RLW - resected liver weight, IWLW - initial whole liver weight, FBW - final body weight, FWLW - final whole liver weight and the three remaining headers are explained in the text. Results were always compared to control Day 0 group, using one-way ANOVA and Tukey`s post hoc test and significant differences $(p<0.05)$ are emphasised in bold text. \%LReg parameter for Day 0 group is set to $100 \%$, to express the fact it is the reference value, although no regeneration occurred in intact animals.

Table 3. Overview of biochemical assessments results.

\begin{tabular}{llllllllll}
\hline Enzyme & Day 0 & Day 1 & Day 2 & Day 3 & Day 5 & Day 7 & Day 9 & Day 11 & Day 14 \\
\hline $\begin{array}{l}A L T \\
(\mu \mathrm{cat} / \mathrm{l})\end{array}$ & $0.7 \pm 0.2$ & $2.1 \pm 1.1$ & $2.2 \pm 0.7$ & $1.9 \pm 0.9$ & $1.1 \pm 0.2$ & $0.8 \pm 0.6$ & $1.0 \pm 0.3$ & $0.9 \pm 0.2$ & $0.8 \pm 0.2$ \\
$\begin{array}{l}A S T \\
(\mu \mathrm{cat} / \mathrm{l})\end{array}$ & $1.5 \pm 0.5$ & $\mathbf{6 . 4} \pm \mathbf{1 . 7}$ & $5.5 \pm 4.0$ & $2.7 \pm 1.1$ & $1.8 \pm 0.1$ & $2.0 \pm 0.4$ & $1.7 \pm 0.1$ & $2.3 \pm 0.6$ & $1.6 \pm 0.1$ \\
\hline
\end{tabular}

Table 3 summarizes data on serum transaminase activities. Data are shown as mean \pm S.D. ( $n=3$ in each group). Results showing significant difference ( $p<0.05$ evaluated by one-way ANOVA and Tukey's post hoc test) compared to control (Day 0 ) group are emphasised in bold text.

We used these two ratios to evaluate the liver mass restoration. This was done by dividing $\mathrm{TC}$ ratio by PH ratio, led by concept published many times, that the liver regains pre-surgery portion of total body weight (Hata et al. 2007, Michalopoulos 2010). Thus we yielded proprietary estimate of completeness of liver regeneration named \%LReg.
Formula:

$$
\% \text { LReg }=\frac{\text { TC ratio }}{\text { PH ratio }} \times 100[\%]
$$

This parameter suggested incomplete organ weight restoration even in the latest observed intervals in our study (Table 2). 

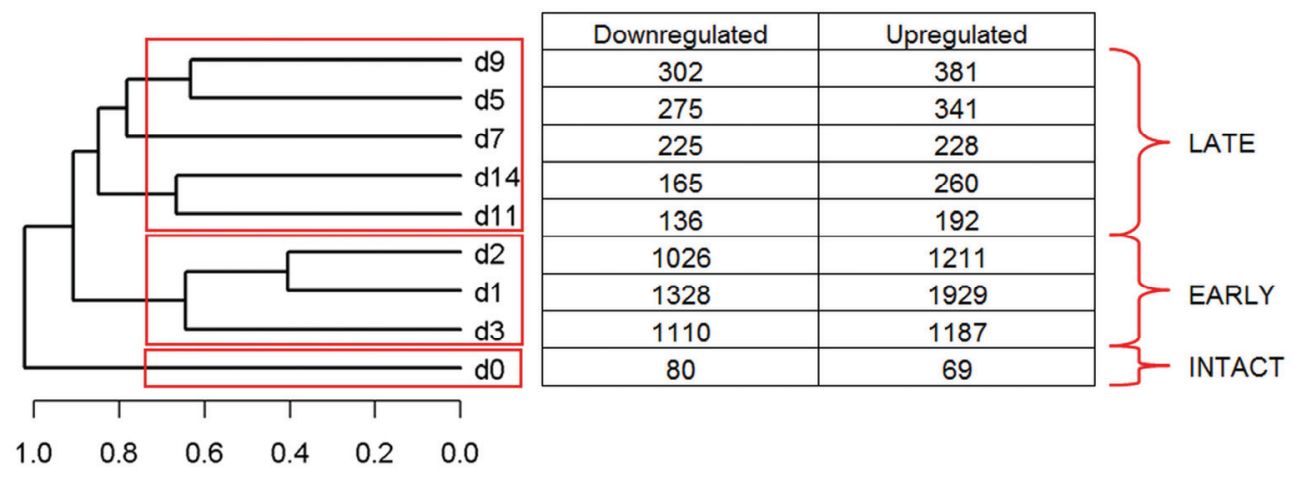

relative distance

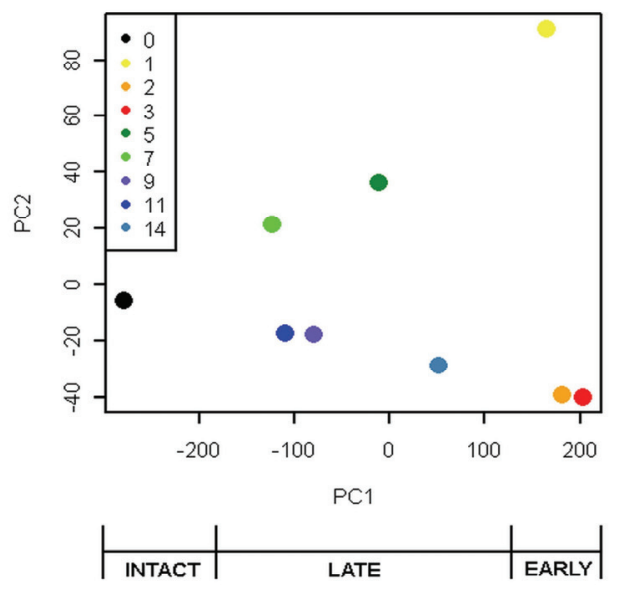

Fig. 1. Results of hierarchical clustering and multiple testing applied on microarray gene expression data and visualization of principal component analysis results. Upper panel: A: More similar days lie closer on a dendrogram and vice versa, showing relationships among intervals of recovery. Branches of the dendrogram converge to reveal the clusters described in the text. Distinction between "Intact", "Early" and "Late" groups is clear. B: The numbers of significantly downregulated or upregulated genes in separate sample groups compared to intact reference. These were obtained by multiple testing performed by limma function decideTests with method "global" and logFC cut-off of |1|. C: The distinguished temporal phases of liver regeneration. Lower panel: Principal component analysis (PCA) reached results concordant to hierarchical clustering although working on different computation principle. Again three groups of time intervals well separated along the first principal component (PC1) were yielded, exactly fitting the above mentioned "Intact", "Early" and "Late" distribution. Axes represent the two dimensions of spatial distribution. Coloured dots stand for individual post-surgery intervals, and the legend stating numbers of respective recovery days is given in the graph inset.

\section{Biochemical measurements}

Aim of biochemical examinations of sera was to reveal possible complications of surgery using liver injury markers (AST and ALT). Biochemical results did not point to such harm. Initial rise in serum activity of both enzymes was expected and is soon resolved (Table 3).

\section{Microarray analysis}

Set of differential expression values among samples of every particular recovery day and a reference sample was the primary outcome of our microarray analysis. Initial dramatic gene expression changes associated with regeneration initiation and hepatocyte proliferation were already described by others (Cimica et al. 2007, Juskeviciute et al. 2008, Togo et al. 2004). However we aimed to focus on regeneration termination taking place on later days. Not having a sure answer to a question when the process actually ends we used two complementary data driven approaches to point our interest.

Thus we subjected primary differential expression data to two independent methods for reducing dimensionality (Causton et al. 2003). The first was unsupervised hierarchical clustering to reveal overall sample group dis/similarity. As shown in Figure 1, the counts of differentially expressed genes decrease along the temporal axis.

Next, a principal component analysis (PCA) was 
applied to the same set of input data as for clustering. First component explained more than $90 \%$ of the data variability (Figure 1). To our best knowledge it is the first time when these approaches were used in effort to refine regeneration termination timing in partial hepatectomy model. Hierarchical clustering yielded three groups of time points of various sizes. Firstly, the intact control group gene expression pattern represented by Day 0 group of array hybridizations segregated alone as "Intact group". That confirmed our expectation of its dissimilarity to both early and later stages of liver regeneration. Secondly, the days 1, 2 and 3 together formed an "Early group" and finally the days 5, 7, 9, 11 and 14 together formed the broadest "Late group". Exactly the same groups were obtained by the PCA analysis (Figure 1), increasing our confidence in using this separation as a reasonable basis for further study.

Keeping the assumption that the gene expression in the latest regeneration phase reflects active termination mechanisms and should therefore be different both from early and intact stages, we continued by comparing the established "Intact", "Early" and "Late" groups. Data used from this step of analysis on were already a secondary microarray output: gene expression indices derived from time contrasts (see Methods). These indices were first compared between "Late" and "Early" group and "Late" and "Intact" group. This yielded 3281 and 801 DEGs in pair wise comparisons and finally 359 genes uniquely altered in the "Late" group, best distinguishing it from both other groups.

These 359 candidate genes were subjected to gene enrichment analysis performed in the web-based Database for Annotation, Visualization and Integrated Discovery (DAVID) (Huang et al. 2009a, Huang et al. 2009b) in order to categorize them by shared functions based on gene annotations in Kyoto Encyclopedia of Genes and Genomes (KEGG) Database (Kanehisa et al. 2002). This advanced computational assessment succeeded to identify five functional groups non-randomly overrepresented among the 359 submitted genes.

These categories/pathways were as follows (with some member genes in brackets):

- PPAR signalling pathway (malic enzyme 1; phospholipid transfer protein; fatty acid binding protein 4; ubiquitin C)

- glycerophospholipid metabolism (diacylglycerol kinase, gamma; lysophospholipase 1; phosphatidic acid phosphatase type 2c; similar to diacyglycerol kinase epsilon)
- complement and coagulation cascades (coagulation factor X; complement component 1, q subcomponent, alpha polypeptide; complement component 4 binding protein, beta; kininogen 1)

- $\quad$ p53 signalling pathway (Cd82 molecule; cytochrome c; protein phosphatase 1D; sestrin 3)

- ribosome (ribosomal protein L24; ribosomal protein L5; ribosomal protein S23; ribosomal protein S9)

Thus we obtained two signalling pathways and three functional categories with less obvious involvement in regulating the liver regeneration. Nevertheless closer look at these pathways revealed multiple relations of their member genes to liver regeneration or to tissue homeostasis in more general view.

\section{RT-PCR analysis}

Identifying the above listed putative regulatory pathways lead us further towards real-time RT-PCR validation of the microarray findings. For RT-PCR validation we decided for genes listed in Table 1. Selection of genes subjected to validation was driven by either their association with the five indicated functional pathways or by their robust and prominent expression changes detected by microarrays. In fact, the functional clustering happened over only 109 of the 359 genes submitted to the database, because the remaining have not had sufficient KEGG annotations. This issue led us to additional approach of manually reviewing all the 359 candidate genes. As a result there were 7 and 4 genes chosen by the two attitudes.

Results of real-time RT-PCR and microarray analyses are presented side by side in Figure 2. Microarray data plotted in the heatmap are time contrasts computed as a comparison of every operated group to the intact control group generated via the common reference. It is a rationale of common reference experimental design to allow for any intergroup comparisons given the use of identical reference throughout all microarray slides (Dobbin and Simon 2002). For real-time RT-PCR $\log _{2}$-transformed levels of gene expression compared to intact control group are shown.

\section{Discussion}

Liver regeneration is crucial in variety of clinical settings (Ibrahim et al. 2005, Yamanaka et al. 1993) and basis for patophysiology and treatment approaches in liver diseases. As so it has been extensively studied in model systems and also in patients. Little understood termination of the regeneration deserves research attention. 
A)

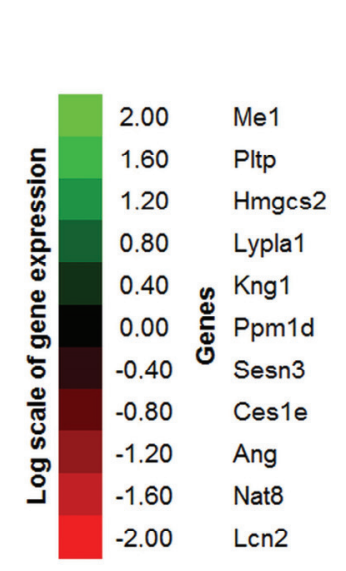

B)
A. MICROARRAYS

Days after resection
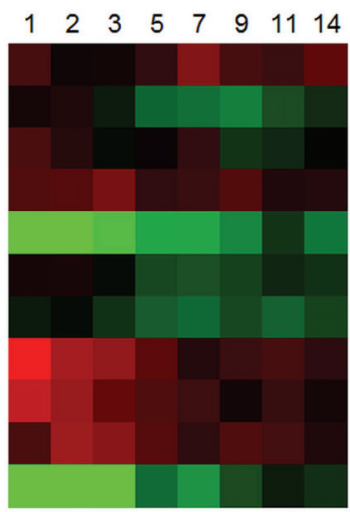

B. REAL-TIME PCR

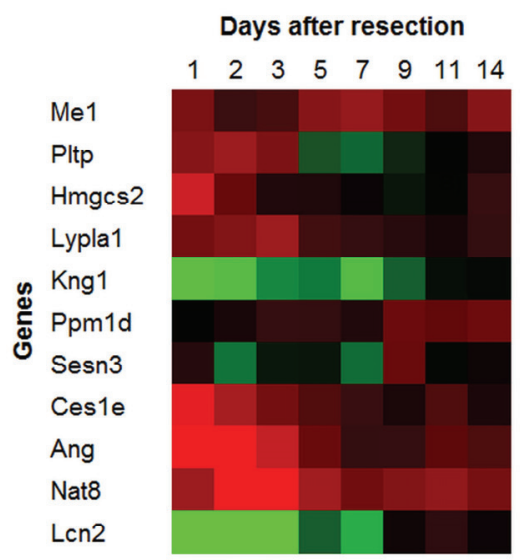

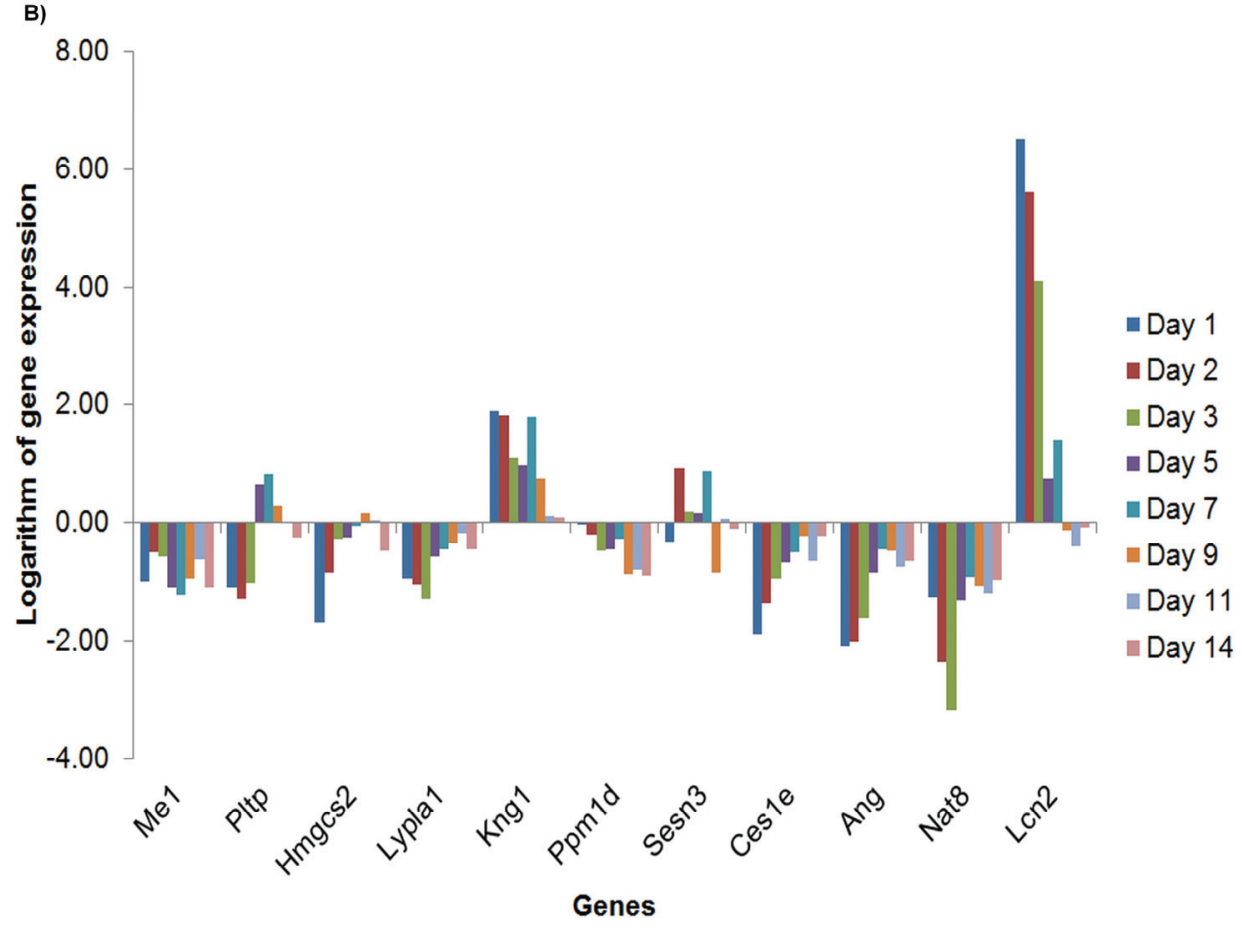

Fig. 2. Results of microarray and RT-PCR analyses and their comparison. Microarray and RT-PCR relative gene expression log ${ }_{2}$ transformed data are displayed side by side. Thanks to this transformation both data sets can be directly compared using unified scale. The reason for using narrower $y$-axis span for heatmaps (A) than that for the graph (B) is that the use of full data range skewed visualization towards black, as most of the values are far from extreme ones. Therefore the heatmap scale was limited to \pm 2 , and exceeding values are shown with the darkest red or green colour used. A) Heatmaps showing gene expression patterns as quantified by both methods employed in the present study. Good overall similarity of results for majority of genes is obvious. Colours indicate direction of gene expression change (red = down- and green = upregulation; see legend). B) Relative gene expression as assessed by real-time RT-PCR. Log $_{2}$-transformed levels of gene expression compared to control group are shown. Values are means from three biological replicates run in PCR triplicates. The six presented genes showed overall time course in good accordance with microarray data. Three more genes were partially concordant and results for two genes were contradictory. Standard deviations are not plotted to keep legibility of the graph. Entire Figure 2 containing standard deviation error bars for the RT-PCR data is provided as supplemental Fig. S2.

Biochemical changes elicited by $2 / 3$ partial hepatectomy in healthy and otherwise untreated rats are mostly of short duration. In our work significant elevation of both serum transaminases did not last past the $2^{\text {nd }}$ day in accord with work of Panis et al. (1997) using larger animal groups. Moreover our transaminase assessments were affected by high variability among animals. However our long term experience supports normalization of both serum enzyme activities until 72 hours after $\mathrm{PH}$.

Looking at timing of regeneration phases: borders of early and late phases are largely arbitrary and set based 
on cell cycle progression of hepatocytes, most numerous liver cells. Thus early phase of liver regeneration would comprise of initiation and proliferation steps and finish around $4^{\text {th }}$ day after $2 / 3$ partial hepatectomy in rats, while late phase with termination events is agreed on to happen in later days (DeFrances and Michalopoulos 2011). However definition of cessation events remains vague and the ultimate completion of the whole process in not sufficiently clarified. Search of related literature shows that restoration of the liver to body mass ratio is commonly noted without the criterion used. Some of the works that presented their estimates of organ regrowth report incomplete mass recovery even in the latest follow-up time points. These observations come both from animal and patient studies (Hockings et al. 2002, Ibrahim et al. 2005). On the other hand there are papers showing complete liver recovery (de Graaf et al. 2008), making conclusions about the "hepatostatic" mechanisms and regeneration timing difficult.

This uncertainty led us to effort of assessing the completeness of liver mass restoration in our present work. We based our calculations on total body and total liver weight data and derived a proprietary parameter \%LReg. Using it, we observed liver weight to reach $83 \pm 9 \%$ of control values at the latest $14^{\text {th }}$ day of study, a difference not statistically significant, however of biological interest. The latest statistically significant difference from controls was seen on $9^{\text {th }}$ day after $2 / 3$ partial hepatectomy, where the \%LReg parameter was merely $77 \pm 11 \%$ (Table 2 ). These results rank our observations among those declaring that the reference value of the "hepatostat", irrespective of what its mechanisms are, is not $100 \%$ of the pre-resection liver to body mass ratio value. Moreover, we evaluated \%LReg parameter in the same experimental settings until $21^{\text {st }}$ day of recovery and there was only mild further rise in liver to body weight ratio (unpublished data).

Unlike most studies in the field aimed at regeneration priming and hepatocyte cell cycle re-entry (Cimica et al. 2007, Juskeviciute et al. 2008, Togo et al. 2004), we focused our work on liver regeneration termination. The two data analysis approaches used in our study place the late phase of regeneration beyond $5^{\text {th }}$ day of recovery however do not provide definitive answer when the regrowth is ceased.

Regarding the microarray and RT-PCR gene expression assessment and their comparison, 9 of 11 results were in good agreement, whereas for the remaining 2 genes the more reliable RT-PCR did not support the microarray findings (Figure 2). No surprise, given the inherent differences and limitations of the methods used, most frequently being detection of various transcript variants. Because the RT-PCR is generally less prone to technical artefacts than microarray analysis, the reactions were performed in triplicates giving them better robustness and RT-PCR technique covers wider dynamic range of transcriptional changes, we will further comment only on RT-PCR relative expression data.

For ease of comprehension, we provide a succinct overview of our results and related reference papers in a form of Table 4.

Hmgcs 2 mediates the first reaction of ketogenesis, a metabolic pathway that provides lipid-derived energy for extrahepatic organs during times of carbohydrate deprivation (Robinson and Williamson 1980). Its expression pattern was in agreement with previous results (Asins et al. 1994, Yuan et al. 2011). Although liver cells initially face starvation-like state early after $\mathrm{PH}$ without limiting ketogenesis and conversely show reduced ketogenesis later when acquiring proliferation competent state, the observed pattern of Hmgcs2 transcription may help to protect liver cells from potentially harmful excess ketone body accumulation. Even more cogent explanation for initial Hmgcs2 downregulation can be seen in saving energy substrates. Indeed, exporting potentially oxidizable fatty acid carbon atoms in the form of ketone bodies, would be wasteful during early days of regeneration (Ockner 2004).

Pltp has a role in cholesterol reverse transport (i.e. from periphery to liver) (Yazdanyar et al. 2011). Liver tissue cholesterol content has been shown to increase after $\mathrm{PH}$ providing necessary membrane building material for regeneration (Abel et al. 2001, Yoshida et al. 1993). Pltp increase would therefore make sense to supply cholesterol for proliferating non-parenchymal liver cells whose division occurs later than that of hepatocytes (Gilgenkrantz and Collin de l'Hortet 2011, Taub 2004). Initial paradoxical decline of Pltp transcription might perhaps be explained by its capacity of transporting lipopolysaccharides equally efficiently as other substrates. Early post-hepatectomy period is joined with increased gut-derived endotoxin influx via portal blood and it is conceivable that liver cells try to limit its intake (Massey et al. 1984). Pltp is also a recognized target of liver $\mathrm{X}$ receptor (LXR) signalling (Cao et al. 2002), which is attenuated early after $\mathrm{PH}$ and normalizes up to the $7^{\text {th }}$ day of recovery (Lo Sasso et al. 2010), thus offering alternative explanation of our observations. 
Table 4. Overview of RT-PCR analysis results and pertinent reference papers.

\begin{tabular}{|c|c|c|c|c|c|c|}
\hline \multirow{3}{*}{$\begin{array}{l}\text { Gene of interest } \\
\text { Hmgcs2 }\end{array}$} & \multirow{3}{*}{$\begin{array}{l}\text { KEGG pathway } \\
\text { rno03320 }\end{array}$} & \multirow{2}{*}{\multicolumn{3}{|c|}{$\begin{array}{c}\text { Gene expression } \\
\text { peak / nadir } \\
\text { according to phases }\end{array}$}} & \multicolumn{2}{|c|}{ Reference papers } \\
\hline & & & & & \multirow{2}{*}{$\begin{array}{c}\text { supporting } \\
1,2,3\end{array}$} & \multirow[t]{2}{*}{ opposing } \\
\hline & & N/A & / & Early & & \\
\hline Pltp & rno03320 & Late & / & Early & $4,5,6$ & 7,8 \\
\hline $\mathrm{Mel}$ & rno03320 & N/A & / & Late & & 1,2 \\
\hline Lypla1 & rno00564 & $\mathrm{N} / \mathrm{A}$ & / & Early & $1,2,9$ & \\
\hline Kngl & rno04610 & Early \& Late & I & $\mathrm{N} / \mathrm{A}$ & 10,11 & \\
\hline Ppmld & rno04115 & N/A & 1 & Late & & 12,13 \\
\hline $\operatorname{Sesn} 3$ & rno04115 & Early \& Late & 1 & Late & & 12,13 \\
\hline Cesle & rno00983 & N/A & I & Early & 1,2 & \\
\hline Len 2 & N/A & Early & 1 & N/A & $14-18$ & \\
\hline Ang & $\mathrm{N} / \mathrm{A}$ & N/A & 1 & Early & 14,19 & \\
\hline Nat8 & N/A & N/A & 1 & Early & 20 & \\
\hline
\end{tabular}

\section{Legend to reference papers}

Number Reference work details (provided in full in the Reference section)

\begin{tabular}{ll}
\hline 1 & Ockner 2004 \\
2 & Yuan et al. 2011 \\
3 & Asins et al. 1994 \\
4 & Massey et al. 1984 \\
5 & Cao et al. 2002 \\
6 & Lo Sasso et al. 2010 \\
7 & Abel et al. 2001 \\
8 & Yoshida et al. 1993 \\
9 & Xu et al. 2008 \\
10 & Aravena et al. 2005 \\
11 & Perez et al. 2006 \\
12 & Sakamoto et al. 1999 \\
13 & Masson et al. 2000 \\
14 & Mohammed and Khokha 2005 \\
15 & Bolignano et al. 2010 \\
16 & Playford et al. 2006 \\
17 & Zhang et al. 2009 \\
18 & Jayaraman et al. 2005 \\
19 & Hu and Riordan 1993 \\
20 & Veiga-da-Cunha et al. 2010 \\
\hline
\end{tabular}

It might be concluded, that we concur with Yuan et al. (2011) regarding multifaceted PPAR signalling pathway involvement in late phase regeneration, discussed in greater detail in their work and in that of Yamamoto et al. (2008). Different counts of member genes may be due to different rat strain and animal group sizes among the studies. Their work also suggested role of fatty acid and other lipid substance metabolism-related pathways, while we sieved glycerophospholipid metabolism pathway as worth attention. Expression pattern of its member Lypla1 was in accord with increased supply of fatty acids from peripheral fat stores during early stages of regeneration (Ockner 2004) and with overall phospholipid catabolism downregulation 
during liver regeneration noted by Xu et al. (2008).

Regarding the role of complement and coagulation cascades member genes, data available to date do not explain their involvement in the late phase of regeneration (Karakoc et al. 2010, Lisman and Porte 2010, Markiewski et al. 2009, Okumura et al. 2007, Sato et al. 2008). We observed markedly increased expression of Kng1 lasting through both "Early" and "Late" phases. Initial increase might be ascribed to its role as acute phase protein and pro-inflammatory reactant, but the sustained elevation suggests its more functions. Stimulatory impact of Kng1 on endothelial cell and fibroblast proliferation has already been documented (Aravena et al. 2005, Perez et al. 2006) and we hypothesize that late phase increase may occur to support non-parenchymal liver cell proliferation. Final Kng1 return to control mRNA levels in the two latest intervals fits this theory.

Regarding the p53 signalling pathway we obtained contradictory gene expression data for both genes tested: Ppm1d and Sesn3, thus we can hardly conclude about them. Previous works did not either included our two candidate genes or did not last to later phases of regeneration (Fan et al. 1998, Tzung et al. 1997, Xu et al. 2007). However apoptosis is clearly an important factor determining final size of the regenerated liver and also an efficiency of the process (Masson et al. 2000, Sakamoto et al. 1999).

Ces1e, a member of Drug metabolism - other enzymes pathway, downregulation pattern is concordant with observation of Yuan et al. (2011) regarding acylCoA synthetase long-chain family member 1 (Acsl1) also acting in long-chain fatty acid catabolism. Excess abundance of long-chain fatty acids exerts adverse effect on mitochondrial function during early phase of regeneration and therefore hepatocytes direct higher proportion of fatty acids to extramitochondrial oxidation in peroxisomes and endoplasmatic reticulum. This adaptation driven by enhanced PPAR $\alpha$ signalling ameliorates oxidative stress and mitochondrial reactive oxygen species production (Ockner 2004). Subsequent normalization of mitochondrial function may allow less restricted utilization of long-chain fatty acids.

Another gene tested was lipocalin 2 also known as neutrophil gelatinase-associated lipocalin (Lcn2 or Ngal). As indicated by its alternative name, Lcn2 forms complexes with gelatinase (matrix metalloprotease 9; MMP-9). These complexes protect MMP-9 from inactivation by tissue inhibitors. MMP-9 mediated cleavage of collagen IV, constituent of basal membranes, allows cells to pass through; thus migrating or invading to new localizations. By this interaction effectively increasing cell motility Lcn2 plays a role in tissue remodelling in multiple situations including gastrointestinal organ wound healing or tumour progression (Bolignano et al. 2010, Playford et al. 2006, Zhang et al. 2009). Tissue remodelling necessarily occurs also during late phase liver regeneration in which disordered clusters of newly proliferated hepatocytes must be rearranged by recovering vessels and extracellular matrix (ECM). However Lcn2 is a multifunctional protein and it has roles to play also in early post-hepatectomy intervals owing to its proinflammatory and bacteriostatic properties and relation to early induced cytokines (interleukin 6 and interleukin $1 \beta$ ) (Jayaraman et al. 2005). Len2 was the most strongly induced gene in our set with steep upregulation in all "Early" days. Multiple biological roles of Lcn2 make hypothesizing about its function during "Early" and "Late" stages of liver regeneration tricky. But it would definitely be interesting to develop and study an Lcn2 knock-out model. Biphasic pattern of interleukin $1 \beta$ upregulation after partial hepatectomy may provide a clue to Lcn2 expression changes (Mohammed and Khokha 2005).

Convincing data support role of Ang, last but one gene in our set, in accelerating plasmin generation (Hu and Riordan 1993). Plasmin itself activates precursors of matrix metalloproteases therefore promoting extracellular matrix degradation with signalling consequences during liver regeneration (Mohammed and Khokha 2005).

Finally the last gene subjected to both microarray and RT-PCR assessment in our study was Nat8, recently identified as a microsomal enzyme that catalyzes the last step of mercapturic acid formation to allow detoxification and excretion of cysteinyl conjugates (Veiga-da-Cunha et al. 2010). Similarly to Ces1e, expression of Nat8 decreased in all "Early" days. Besides xenobiotics also some leukotrienes are among Nat8 substrates, suggesting further roles of this enzyme during liver regeneration.

\section{Conclusions}

To summarize all the findings, we conclude the following. Transcriptional control of late phase liver regeneration in a rat 2/3 partial hepatectomy model was 
studied, motivated by the lack of its understanding and high clinical relevance. We performed microarray gene expression profiling during experiment with rather exceptionally wide range of recovery times, spanning up to 14 days after the surgery. Longer than usual postsurgery follow up paid off in better coverage of the time dynamics of the process and is advisable for further works. Innovative combination of hierarchical clustering and principal component analysis of microarray data resulted in accord in distinction of three temporal phases of liver regenerative response. Late phase appeared different from both early and intact phases of regeneration, supporting validity of our assumption that active termination mechanisms exist. The late stage, mapped beyond the $5^{\text {th }}$ recovery day, was focus of further analyses.

Computational pathway analysis and manual review of 359 genes found to be specific for the late phase revealed five gene functional groups highly probably involved in the advanced regeneration. Both automated and manual interpretation approaches gave better results than any of them alone and their combination is justified.

Our findings were achieved using a novel combination of bioinformatic genome-scale data processing methods and substantiated by widely trusted real-time RT-PCR assessment. Taking posttranscriptional regulation mechanisms into account, our results form reasonable basis for subsequent research studies in a vivid field of liver regeneration. Although no mechanistic explanations can be drawn based on sole gene expression data, present study provides clues to direct further investigation. Improved knowledge about pathways driving termination of liver cell proliferation would be valuable in prevention and therapy of liver tumours. These are nowadays hard to treat and liver resections with curative intention are joined with discouraging complications (Ezzat et al. 2011).

\section{Conflict of Interest}

Part of the research expenses was covered by industrysponsored grant provided by GENERI BIOTECH s.r.o.; however this funding was not associated with lack of access to data, or lack of control of the decision to publish, or any other potential conflict or constraints. D. R., L. H., A. V., A. L. and M. B. still are or were employed with GENERI BIOTECH s.r.o. during the duration of study; however none of them received any money or benefits for work described in the present paper. Z. $\breve{C}$. has no conflict of interest to declare.

\section{Acknowledgements}

This study was supported by Ministry of Education grant No. MSM 0021620820, Charles University Grant Agency grant No. 9945/2009(94509), grant from Charles University No. SVV-2011-262901 and industrysponsored grant provided by GENERI BIOTECH s.r.o.

\section{References}

ABEL S, SMUTS CM, DE VILLIERS C, GELDERBLOM WC: Changes in essential fatty acid patterns associated with normal liver regeneration and the progression of hepatocyte nodules in rat hepatocarcinogenesis. Carcinogenesis 22: 795-804, 2001.

ANDERSEN CL, JENSEN JL, ORNTOFT TF: Normalization of real-time quantitative reverse transcription-PCR data: a model-based variance estimation approach to identify genes suited for normalization, applied to bladder and colon cancer data sets. Cancer Res 64: 5245-5250, 2004.

APTE U, GKRETSI V, BOWEN WC, MARS WM, LUO JH, DONTHAMSETTY S, ORR A, MONGA SP, WU C, MICHALOPOULOS GK: Enhanced liver regeneration following changes induced by hepatocyte-specific genetic ablation of integrin-linked kinase. Hepatology 50: 844-851, 2009.

ARAVENA M, PEREZ C, PEREZ V, ACUNA-CASTILLO C, GOMEZ C, LEIVA-SALCEDO E, NISHIMURA S, SABAJ V, WALTER R, SIERRA F: T-kininogen can either induce or inhibit proliferation in Balb/c 3T3 fibroblasts, depending on the route of administration. Mech Ageing Dev 126: 399-406, 2005.

ASINS G, ROSA JL, SERRA D, GIL-GOMEZ G, AYTE J, BARTRONS R, TAULER A, HEGARDT FG: Gene expression of enzymes regulating ketogenesis and fatty acid metabolism in regenerating rat liver. Biochem $J$ 299: 65-69, 1994.

BECKER RA, CHAMBERS JM, WILKS AR: The New S Language: A Programming Environment for Data Analysis and Graphics. Wadsworth \& Brooks/Cole Advanced Books \& Software, Pacific Grove, 1988. 
BOLIGNANO D, DONATO V, LACQUANITI A, FAZIO MR, BONO C, COPPOLINO G, BUEMI M: Neutrophil gelatinase-associated lipocalin (NGAL) in human neoplasias: a new protein enters the scene. Cancer Lett 288 : 10-16, 2010.

CAO G, BEYER TP, YANG XP, SCHMIDT RJ, ZHANG Y, BENSCH WR, KAUFFMAN RF, GAO H, RYAN TP, LIANG Y, EACHO PI, JIANG XC: Phospholipid transfer protein is regulated by liver X receptors in vivo. J Biol Chem 277: 39561-39565, 2002.

CAUSTON HC, QUACKENBUSH J, BRAZMA A: Microarray Gene Expression Data Analysis: A Beginner `s Guide. Blackwell Publishing, Bodmin, 2003.

CIMICA V, BATUSIC D, HARALANOVA-ILIEVA B, CHEN Y, HOLLEMANN T, PIELER T, RAMADORI G: Serial analysis of gene expression (SAGE) in rat liver regeneration. Biochem Biophys Res Commun 360: 545$552,2007$.

DE GRAAF W, VETELÄINEN RL, DE BRUIN K, VAN VLIET AK, VAN GULIK TM, BENNINK RJ: 99mTc-GSA scintigraphy with SPECT for assessment of hepatic function and functional volume during liver regeneration in a rat model of partial hepatectomy. $J$ Nucl Med 49: 122-128, 2008.

DEFRANCES MC, MICHALOPOULOS GK: Liver regeneration and partial hepatectomy: process and prototype. In: Liver Regeneration. D HÄUSSINGER (ed), Walter de Gruyter GmbH \& Co. KG, Berlin/Boston, 2011, pp 116.

DELGADO-COELLO B, BRIONES-ORTA MA, MACIAS-SILVA M, MAS-OLIVA J: Cholesterol: recapitulation of its active role during liver regeneration. Liver Int 31: 1271-1284, 2011.

DOBBIN K, SIMON R: Comparison of microarray designs for class comparison and class discovery. Bioinformatics 18: 1438-1445, 2002.

DOBBIN KK, KAWASAKI ES, PETERSEN DW, SIMON RM: Characterizing dye bias in microarray experiments. Bioinformatics 21: 2430-2437, 2005.

EZZAT TM, DHAR DK, NEWSOME PN, MALAGO M, OLDE DAMINK SW: Use of hepatocyte and stem cells for treatment of post-resectional liver failure: are we there yet? Liver Int 31: 773-784, 2011.

FAN G, KREN BT, STEER CJ: Regulation of apoptosis-associated genes in the regenerating liver. Semin Liver Dis 18: 123-140, 1998.

FAUSTO N, RIEHLE KJ: Mechanisms of liver regeneration and their clinical implications. J Hepatobiliary Pancreat Surg 12: 181-189, 2005.

GILGENKRANTZ H, COLLIN DE L'HORTET A: New insights into liver regeneration. Clin Res Hepatol Gastroenterol 35: 623-629 2011.

GIRKE T: $R \&$ Bioconductor Manual. http://manuals.bioinformatics.ucr.edu/home/R_BioCondManual\#BIOCONPROGRAMS [cited 20. 05. 2012].

GORDON AD: Classification. Chapman \& Hall/CRC, London, 1999.

HATA S, NAMAE M, NISHINA H: Liver development and regeneration: from laboratory study to clinical therapy. Dev Growth Differ 49: 163-170, 2007.

HIGGINS GM, ANDERSON RM: Experimental pathology of the liver. I. Restoration of the liver of the white rat following partial surgical removal. Arch Pathol (Chic) 12: 186-202, 1931.

HOCKINGS PD, ROBERTS T, CAMPBELL SP, REID DG, GREENHILL RW, POLLEY SR, NELSON P, BERTRAM TA, KRAMER K: Longitudinal magnetic resonance imaging quantitation of rat liver regeneration after partial hepatectomy. Toxicol Pathol 30: 606-610, 2002.

HU GF, RIORDAN JF: Angiogenin enhances actin acceleration of plasminogen activation. Biochem Biophys Res Commun 197: 682-687, 1993.

HUANG DW, SHERMAN BT, LEMPICKI RA: Systematic and integrative analysis of large gene lists using DAVID Bioinformatics Resources. Nature Protocols 4: 44-57, 2009a.

HUANG DW, SHERMAN BT, LEMPICKI RA: Bioinformatics enrichment tools: paths toward the comprehensive functional analysis of large gene lists. Nucleic Acids Res 37: 1-13, $2009 \mathrm{~b}$.

HUANG W, MA K, ZHANG J, QATANANI M, CUVILLIER J, LIU J, DONG B, HUANG X, MOORE DD: Nuclear receptor-dependent bile acid signaling is required for normal liver regeneration. Science 312: 233-236, 2006. 
IBRAHIM S, CHEN CL, WANG CC, WANG SH, LIN CC, LIU YW, YANG CH, YONG CC, CONCEJERO A, CHENG YF: Liver regeneration and splenic enlargement in donors after living-donor liver transplantation. World J Surg 29: 1658-1666, 2005.

IMAI T: Functional genetic dissection of nuclear receptor signalling in obesity, diabetes and liver regeneration using spatiotemporally controlled somatic mutagenesis in the mouse. Keio J Med 52: 198-203, 2003.

JAYARAMAN A, ROBERTS KA, YOON J, YARMUSH DM, DUAN X, LEE K, YARMUSH ML: Identification of neutrophil gelatinase-associated lipocalin (NGAL) as a discriminatory marker of the hepatocyte-secreted protein response to IL-1beta: a proteomic analysis. Biotechnol Bioeng 91: 502-515, 2005.

JUSKEVICIUTE E, VADIGEPALLI R, HOEK JB: Temporal and functional profile of the transcriptional regulatory network in the early regenerative response to partial hepatectomy in the rat. BMC Genomics 9: 527, 2008.

KANEHISA M, GOTO S, KAWASHIMA S, NAKAYA A: The KEGG databases at GenomeNet. Nucleic Acids Res 30: 42-46, 2002.

KARAKOC D, HAMALOGLU E, OZDEMIR A, DOGRUL A, OZENC A: The effect of hepatectomy on coagulation: an evaluation by thromboelastography. Eur J Gastroenterol Hepatol 22: 43-48, 2010.

LISMAN T, PORTE RJ: The role of platelets in liver inflammation and regeneration. Semin Thromb Hemost 36: 170$174,2010$.

LO SASSO G, CELLI N, CABONI M, MURZILLI S, SALVATORE L, MORGANO A, VACCA M, PAGLIANI T, PARINI P, MOSCHETTA A: Down-regulation of the LXR transcriptome provides the requisite cholesterol levels to proliferating hepatocytes. Hepatology 51: 1334-1344, 2010.

MARKIEWSKI MM, DEANGELIS RA, STREY CW, FOUKAS PG, GERARD C, GERARD N, WETSEL RA, LAMBRIS JD: The regulation of liver cell survival by complement. J Immunol 182: 5412-5418, 2009.

MASSEY JB, HICKSON D, SHE HS, SPARROW JT, VIA DP, GOTTO AM, JR., POWNALL HJ: Measurement and prediction of the rates of spontaneous transfer of phospholipids between plasma lipoproteins. Biochim Biophys Acta 794: 274-280, 1984.

MASSON S, SCOTTE M, GARNIER S, FRANCOIS A, HIRON M, TENIERE P, FALLU J, SALIER JP, DAVEAU M: Differential expression of apoptosis-associated genes post-hepatectomy in cirrhotic vs. normal rats. Apoptosis 5: 173-179, 2000.

MICHALOPOULOS GK: Liver regeneration. J Cell Physiol 213: 286-300, 2007.

MICHALOPOULOS GK: Liver regeneration after partial hepatectomy: critical analysis of mechanistic dilemmas. Am $J$ Pathol 176: 2-13, 2010.

MOHAMMED FF, KHOKHA R: Thinking outside the cell: proteases regulate hepatocyte division. Trends Cell Biol 15: $555-563,2005$.

NGUYEN LN, FURUYA MH, WOLFRAIM LA, NGUYEN AP, HOLDREN MS, CAMPBELL JS, KNIGHT B, YEOH GC, FAUSTO N, PARKS WT: Transforming growth factor-beta differentially regulates oval cell and hepatocyte proliferation. Hepatology 45: 31-41, 2007.

OCKNER RK: Metabolism and gene expression in liver regeneration. In: Integration of Metabolism, Energetics, and Signal Transduction. Kluwer Academic / Plenum Publishers, New York, 2004, pp 177-200.

OKUMURA N, SEKI T, ARIGA T: Cell surface-bound plasminogen regulates hepatocyte proliferation through a uPAdependent mechanism. Biosci Biotechnol Biochem 71: 1542-1549, 2007.

PALMES D, SPIEGEL HU: Animal models of liver regeneration. Biomaterials 25: 1601-1611, 2004.

PANIS Y, MCMULLAN DM, EMOND JC: Progressive necrosis after hepatectomy and the pathophysiology of liver failure after massive resection. Surgery 121: 142-149, 1997.

PEREZ V, LEIVA-SALCEDO E, ACUNA-CASTILlO C, ARAVENA M, GOMEZ C, SABAJ V, COLOMBO A, NISHIMURA S, PEREZ C, WALTER R, SIERRA F: T-kininogen induces endothelial cell proliferation. Mech Ageing Dev 127: 282-289, 2006.

PFAFFL MW: A new mathematical model for relative quantification in real-time RT-PCR. Nucleic Acids Res 29: e45, 2001. 
PLAYFORD RJ, BELO A, POULSOM R, FITZGERALD AJ, HARRIS K, PAWLUCZYK I, RYON J, DARBY T, NILSEN-HAMILTON M, GHOSH S, MARCHBANK T: Effects of mouse and human lipocalin homologues $24 \mathrm{p} 3 / \mathrm{lcn} 2$ and neutrophil gelatinase-associated lipocalin on gastrointestinal mucosal integrity and repair. Gastroenterology 131: 809-817, 2006.

ROBINSON AM, WILLIAMSON DH: Physiological roles of ketone bodies as substrates and signals in mammalian tissues. Physiol Rev 60: 143-187, 1980.

SAKAMOTO T, LIU Z, MURASE N, EZURE T, YOKOMURO S, POLI V, DEMETRIS AJ: Mitosis and apoptosis in the liver of interleukin-6-deficient mice after partial hepatectomy. Hepatology 29: 403-411, 1999.

SATO Y, NAKATSUKA H, YAMAMOTO S, OYA H, KOBAYASHI T, WATANABE T, KOKAI H, KUROSAKI I, SHIRAI Y, HATAKEYAMA K: Coagulation and fibrinolytic systems during liver regeneration in the early period after adult living related partial liver transplantation. Transplant Proc 40: 2501-2502, 2008.

SMYTH GK: Linear models and empirical Bayes methods for assessing differential expression in microarray experiments. Stat Appl Genet Mol Biol 3: Article 3, 2004.

SMYTH GK, SPEED T: Normalization of cDNA microarray data. Methods 31: 265-273, 2003.

STEKEL D: Microarray Bioinformatics. Cambridge University Press, 2003.

TAUB R: Liver regeneration: from myth to mechanism. Nat Rev Mol Cell Biol 5: 836-847, 2004.

TINIAKOS DG, KANDILIS A, GELLER SA: Tityus: a forgotten myth of liver regeneration. J Hepatol 53: 357-361, 2010.

TOGO S, MAKINO H, KOBAYASHI T, MORITA T, SHIMIZU T, KUBOTA T, ICHIKAWA Y, ISHIKAWA T, OKAZAKI Y, HAYASHIZAKI Y, SHIMADA H: Mechanism of liver regeneration after partial hepatectomy using mouse cDNA microarray. J Hepatol 40: 464-471, 2004.

TZUNG SP, FAUSTO N, HOCKENBERY DM: Expression of Bcl-2 family during liver regeneration and identification of Bcl-x as a delayed early response gene. Am J Pathol 150: 1985-1995, 1997.

VANDESOMPELE J, DE PRETER K, PATTYN F, POPPE B, VAN ROY N, DE PAEPE A, SPELEMAN F: Accurate normalization of real-time quantitative RT-PCR data by geometric averaging of multiple internal control genes. Genome Biol 3: research0034.1-research0034.11, 2002.

VEIGA-DA-CUNHA M, TYTECA D, STROOBANT V, COURTOY PJ, OPPERDOES FR, VAN SCHAFTINGEN E: Molecular identification of NAT8 as the enzyme that acetylates cysteine S-conjugates to mercapturic acids. J Biol Chem 285: 18888-18898, 2010.

VENABLES WN, RIPLEY BD: Modern Applied Statistics with S. Springer Verlag, 2002.

WANG YD, CHEN WD, MOORE DD, HUANG W: FXR: a metabolic regulator and cell protector. Cell Res 18: $1087-$ 1095, 2008.

XU C, LIN F, QIN S: Relevance between lipid metabolism-associated genes and rat liver regeneration. Hepatol Res 38: $825-837,2008$.

XU CS, ZHANG SB, CHEN XG, RAHMAN S: Correlation analysis of liver tumor-associated genes with liver regeneration. World J Gastroenterol 13: 3323-3332, 2007.

YAMAMOTO Y, ONO T, DHAR DK, YAMANOI A, TACHIBANA M, TANAKA T, NAGASUE N: Role of peroxisome proliferator-activated receptor-gamma (PPARgamma) during liver regeneration in rats. $J$ Gastroenterol Hepatol 23: 930-937, 2008.

YAMANAKA N, OKAMOTO E, KAWAMURA E, KATO T, ORIYAMA T, FUJIMOTO J, FURUKAWA K, TANAKA T, TOMODA F, TANAKA W: Dynamics of normal and injured human liver regeneration after hepatectomy as assessed on the basis of computed tomography and liver function. Hepatology 18: 79-85, 1993.

YAZDANYAR A, YEANG C, JIANG XC: Role of phospholipid transfer protein in high-density lipoprotein- mediated reverse cholesterol transport. Curr Atheroscler Rep 13: 242-248, 2011.

YOSHIDA M, TANAKA J, TAMURA J, FUJTA K, KASAMATSU T, KOHMOTO M, TOBE T: Altered fluidity of liver plasma membranes following partial hepatectomy in rats. J Surg Res 55: 390-396, 1993.

YUAN X, YAN S, ZHAO J, SHI D, YUAN B, DAI W, JIAO B, ZHANG W, MIAO M: Lipid metabolism and peroxisome proliferator-activated receptor signaling pathways participate in late-phase liver regeneration. J Proteome Res 10: 1179-1190, 2011. 
ZHANG XF, ZHANG Y, ZHANG XH, ZHOU SM, YANG GG, WANG OC, GUO GL, YANG GY, HU XQ: Clinical significance of Neutrophil gelatinase-associated lipocalin(NGAL) expression in primary rectal cancer. BMC Cancer 9: 134, 2009. 